\title{
The Role of Sensor-Activated Faucets in Surgical Handwashing Environment as a Reservoir of Legionella
}

\author{
Marta Mazzotta ${ }^{1} \oplus$, Luna Girolamini ${ }^{1}$, Maria Rosaria Pascale ${ }^{1}$, Jessica Lizzadro ${ }^{1}$, \\ Silvano Salaris ${ }^{1}$, Ada Dormi ${ }^{2}$ and Sandra Cristino ${ }^{1, *(\mathbb{D}}$ \\ 1 Department of Biological, Geological, and Environmental Sciences, University of Bologna, \\ via San Giacomo 12, 40126 Bologna, Italy; marta.mazzotta2@unibo.it (M.M.); \\ luna.girolamini2@unibo.it (L.G.); mariarosaria.pascal2@unibo.it (M.R.P.); \\ jessica.lizzadro2@unibo.it (J.L.); silvano.salaris@unibo.it (S.S.) \\ 2 Department of Medical and Surgical Science, University of Bologna, via San Giacomo 12, \\ 40126 Bologna, Italy; ada.dormi@unibo.it \\ * Correspondence: sandra.cristino@unibo.it; Tel.: +39-051-209-4811; Fax: +39-051-209-4829
}

Received: 3 May 2020; Accepted: 3 June 2020; Published: 5 June 2020

\begin{abstract}
Surgical handwashing is a mandatory practice to protect both surgeons and patients in order to control Healthcare-Associated Infections (HAIs). The study is focused on Legionella and Pseudomonas aeruginosa contamination in Surgical Handwashing Outlets (SHWOs) provided by sensor-activated faucets with Thermostatic Mixer Valves (TMVs), as correlated to temperature, technologies, and disinfection used. Samples were analyzed by standard culture techniques, comparing hot- and cold-water samples. Legionella isolates were typed by an agglutination test and by mip sequencing. Legionella contamination showed the same distribution between hot and cold samples concerning positive samples and mean concentration: $44.5 \%$ and $1.94 \log _{10} \mathrm{cfu} / \mathrm{L}$ vs. $42.6 \%$ and $1.81 \log _{10} \mathrm{cfu} / \mathrm{L}$, respectively. Regarding the distribution of isolates (Legionella pneumophila vs. Legionella non-pneumophila species), significant differences were found between hot- and cold-positive samples. The contamination found in relation to ranges of temperature showed the main positive samples $\left(47.1 \%\right.$ ) between $45.1-49.6^{\circ} \mathrm{C}$, corresponding to high Legionella concentrations (2.17 $\log _{10}$ $\mathrm{cfu} / \mathrm{L})$. In contrast, an increase of temperature $\left(>49.6^{\circ} \mathrm{C}\right)$ led to a decrease in positive samples $(23.2 \%)$ and mean concentration $\left(1.64 \log _{10} \mathrm{cfu} / \mathrm{L}\right)$. A low level of Pseudomonas aeruginosa was found. For SHWOs located in critical areas, lack of consideration of technologies used and uncorrected disinfection protocols may lead to the development of a high-risk environment for both patients and surgeons.
\end{abstract}

Keywords: Healthcare-Associated Infections (HAIs); Surgical Handwashing Outlets (SHWOs); sensor-activated faucets; Legionella spp.; risk assessment plan

\section{Introduction}

Nosocomial infections, also known as Healthcare-Associated Infections (HAIs), are defined as infections which were absent at the time of hospital admission that a patient acquires during their stay in a hospital or other healthcare facilities [1]. Populations that are at risk for HAIs are immunocompromised patients in Intensive Care Units (ICUs), those in burn units, those undergoing organ transplants, or older patients and neonates. Extensive studies have been carried out by the World Health Organization (WHO) showing that the most frequent nosocomial infections globally include catheter-associated urinary tract infections, central-line associated bloodstream infections, ventilator-associated pneumonia, and surgical site infections [1]. 
It has been estimated that, in Italy, $5-8 \%$ of hospitalized patients contract nosocomial infections every year and 450,000-700,000 HAIs occur in hospitalized patients; these data refer to urinary infections, followed by infections of surgical wounds, pneumonia, and sepsis [2,3].

Risk factors that promote nosocomial infections-other than patient susceptibility, such as immunosuppressed patients in ICUs-include poor hygienic conditions such as improper hand hygiene of Healthcare Staff (HCS) or contaminated air and water [1]. The water supply system in hospitals may constitute a source of HAIs caused by opportunistic pathogens such as Pseudomonas aeruginosa (P. aeruginosa), Legionella spp., Acinetobacter species, and fungi $[4,5]$. These organisms are transmitted by direct or indirect contact with water or by inhalation of aerosol generated by a water source [6-8]. Legionella spp. are ubiquitous aquatic organisms associated with community-acquired pneumoniae as well as hospital-acquired pneumonia. Direct inhalation of aerosols from environmental colonization is typically the source of infection. As Legionella infection is not spread between humans, environmental monitoring of potable water, cooling towers, and related sources is crucial to control the incidence of disease. Legionella is able to survive for long periods in water and even to replicate in the presence of disinfectants and some conditions (e.g., pipeline materials, stagnation and sludge formation, parasitism of amoebas and protozoic cysts, and so on) [9].

In recent years, the increasing incidence of both nosocomial and community-acquired Legionella infections has been a major public health concern: in 2018, 2964 cases were notified to the National Surveillance System in Italy, with an incidence of 48.9 cases per million inhabitants with lethality rate for community and healthcare cases of $10.9 \%$ and $51.7 \%$, respectively [10].

The risk of illness increases dramatically if the germ is found in certain wards such as ICUs, hematology-oncology units, cardiology units, hemodialysis units, and pulmonology units due to the critical nature of these wards for their hospitalized patients [11]. Nevertheless, the real risk of other sources of infection remains partially underestimated when making a correct Legionella risk assessment plan in water systems, such as suggested by the Italian Guidelines as the correct strategy to minimize the risk of colonization [12].

Different guidelines and studies have suggested that water outlets for handwashing in hospitals are frequently contaminated with P. aeruginosa and other Gram-negative bacteria, such as Legionella, which have been linked to nosocomial infections $[8,13]$. In particular, the presence of Legionella in outlets poses a risk of infection during handwashing practices due to aerosol generation.

The key factors for prevention of HAIs in the surgical area are associated with hand hygiene, surgeon handwashing characteristics, and appropriately timed glove use. Hand hygiene is an extremely important measure implemented to reduce HAIs; the WHO published guidelines in 2006 and in 2009 for routine and surgical hand hygiene protocols directed to control resident flora as well as transient microflora $[14,15]$. There are two primary methods for hand hygiene: antimicrobial or non-antimicrobial soap and water scrub, called the "scrub method", and Alcohol-Based Hand Rub, called the "rub method" [16]. Concerning the surgeon handwashing station characteristics, they are generally made entirely of stainless steel with a tank made of a single plate to guarantee the continuity of the surfaces and to avoid all possible areas of bacterial proliferation (e.g., spaces or grooves). The front part is slanted by $30^{\circ}$ in order to prevent splashing and direct water contact with operators [17].

Moreover, surgical handwashing points are equipped with two main types of faucets: manual faucets, with a long clinical lever that dispenses and mixes water by use of the elbow or foot to avoid direct contact with the hands, or non-touch water taps, provided with photocell-operated water supply as electronically managed by a photocell sensor, some of them provided by Thermostatic Mixer Valves (TMVs) [18].

Non-touch water taps, also called sensor-activated faucets with TMVs, have been gradually introduced into private and public hospital facilities to prevent patients or HCS from risk of acquiring infection or transferring infection during surgical procedures by touching contaminated taps. These taps work only when the hands are put in front of a magnetic/sensor valve which causes water to flow out and, when hands are removed, the water flow to stop. The presence of a TMV permits the flushing 
of water through a single pipeline at a fixed temperature (generally about $36^{\circ} \mathrm{C}$ ). The mixing is due to the presence of a cartridge which is able to recall cold water, leading to the desired temperature when mixed with hot water. Hospitals and other healthcare facilities where hygienic measures are very important have started to install this type of touch-free tap system to promote lower water consumption, thus saving costs and preventing HCS from potential recontamination upon hand contact with faucet valves [18]. However, there are no current data that support a decrease in HAIs associated with the use of non-touch water taps [19].

Periodic monitoring of the presence of Legionella or other waterborne pathogens in all outlets used for hand hygiene-in particular, during the preoperative phases of hand hygiene in surgeons-represents a preventive measure to avoid handwashing contamination before starting surgical procedures and to control the possible exposure of patients and health professionals.

Our research is presented as the result of a Legionella environmental monitoring program, conducted from 2013 to 2019 in 11 hospitals located in different regions of Italy. The analysis of data has identified, as critical points, 52 Surgical Handwashing Outlets (SHWOs) provided by sensor-activated faucets with TMVs with high levels of Legionella contamination.

The focus of the study is the analysis of microbiological contamination of SHWOs concerning Legionella and P. aeruginosa, comparing hot- and cold-water samples supplied by a municipal distribution system. The data obtained are also studied in relation to the SHWO temperatures measured as well as compare the SHWOs technologies-sensor-activated faucets with TMVs versus manual clinical valves without TMVs- to understand the key elements of contamination that could develop a reservoir for Legionella and could enhance the risk of infection.

\section{Results}

All results are presented, first of all, by considering the general contamination found in SHWOs and, then later, by dividing Legionella contamination between hot- and cold-water samples. The data about Legionella concentration are expressed in $\log _{10} \mathrm{cfu} / \mathrm{L}$ (Log cfu/L).

The same method is used to correlate the microbial contamination found with temperature values measured in SHWOs and their distribution between hot- and cold-water samples.

\subsection{Legionella Contamination in SHWOs}

The results of mean Legionella concentrations found in 52 SHWOs from 11 hospitals are shown in Figure 1. Seven of the hospitals showed Legionella contamination $(7 / 11,63.6 \%)$, where three $(3 / 7,42.8 \%)$ of them showed values over the level of risk indicated by Italian Guidelines, that is, at $>100 \mathrm{cfu} / \mathrm{L}$ $(>2 \mathrm{Log} \mathrm{cfu} / \mathrm{L})$ [12]. The contamination was found in hot or cold samples and in both water distribution systems for each hospital.

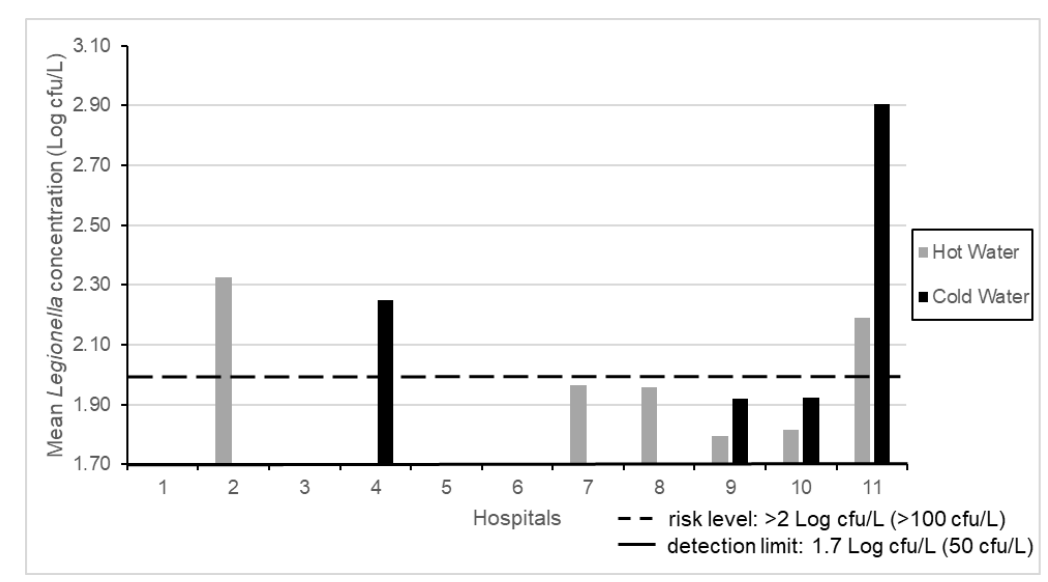

Figure 1. Mean Legionella concentrations in 11 hospitals. 
The results of microbial contamination from 669 SHWO samples show that Legionella was detected in $293 / 669(43.8 \%)$ of samples.

An analysis of Legionella contamination was then performed between hot-water $(n=427)$ and cold-water samples $(n=242)$. The differences between the numbers of hot- and cold-water samples were linked to a higher concentration of Legionella found in hot-water samples which, according to the suggestions of the Italian Guidelines, requires resampling from the same positive outlets [12].

In particular, the analysis of results between hot- and cold-water distribution systems showed 190/427 (44.5\%) of positive hot-water samples and 103/242 (42.6\%) positive cold-water samples. The positive samples over the Legionella level of risk (>2 Log cfu/L) were 140/190 (73.7\%) for hot- and $70 / 103(68.0 \%)$ for cold-water samples.

In Table 1, the data of mean temperature and disinfectant residue with relative minimum (min) and maximum (max) values, the percentage of Legionella positive samples, mean concentrations, and the range of contamination (min-max) found in hot and cold-water samples are listed, respectively. Data about temperature, disinfectant residues, and Legionella concentration are expressed as mean \pm Standard Deviation (SD).

Table 1. Surgical Handwashing Outlet (SHWO) microbiological and physical-chemical parameters measured: hot- vs. cold-water samples.

\begin{tabular}{|c|c|c|c|c|c|c|}
\hline $\begin{array}{c}\text { SHWO } \\
\text { Distribution } \\
\text { Systems }\end{array}$ & $\begin{array}{c}\text { Temperature } \\
\text { Mean } \pm \text { SD } \\
\text { (Min-Max) } \\
\left({ }^{\circ} \mathrm{C}\right)\end{array}$ & $\begin{array}{c}\mathrm{H}_{2} \mathrm{O}_{2} \text { Residue } \\
\text { Mean } \pm \text { SD } \\
(\mathrm{Min}-\mathrm{Max}) \\
(\mathrm{mg} / \mathrm{L})\end{array}$ & $\begin{array}{c}\text { Number of } \\
\text { Total SHWO } \\
\text { Water Samples }\end{array}$ & $\begin{array}{l}\text { Number of } \\
\text { Legionella-Positive } \\
\text { Samples/Total } \\
\text { Samples } \\
(\%)\end{array}$ & $\begin{array}{l}\text { Legionella } \\
\text { Concentration } \\
\text { Mean } \pm \text { SD } \\
(\text { Min-Max) } \\
(\text { Log cfu/L) }\end{array}$ & $\begin{array}{c}\text { Mean Legionella } \\
\text { Concentration Comparison } \\
\text { Hot vs. Cold Samples } \\
\text { Mann-Whitney Test } \\
p \text {-Value }(p)\end{array}$ \\
\hline $\begin{array}{c}\text { Hot } \\
\text { water samples }\end{array}$ & $\begin{array}{l}47.7 \pm 4.95 \\
(21.9-60.1)\end{array}$ & $\begin{array}{c}10 \pm 6.67 \\
(5-25)\end{array}$ & 427 & $\begin{array}{c}190 / 427 \\
(44.5)\end{array}$ & $\begin{array}{c}1.94 \pm 1.07 \\
(1.70-5.8)\end{array}$ & \multirow[b]{2}{*}{0.34} \\
\hline $\begin{array}{c}\text { Cold } \\
\text { water } \\
\text { samples }\end{array}$ & $\begin{array}{c}19.1 \pm 4.38 \\
(9.2-44.7)\end{array}$ & $\begin{array}{c}2.5 \pm 1.5 \\
(0.5-5)\end{array}$ & 242 & $\begin{array}{c}103 / 242 \\
(42.6)\end{array}$ & $\begin{array}{c}1.81 \pm 0.88 \\
(1.70-4.7)\end{array}$ & \\
\hline
\end{tabular}

No significant difference $(p=0.34)$ is found between hot and cold samples concerning Legionella levels.

Regarding the Legionella isolates distribution in SHWOs between hot- and cold-positive samples, the results showed samples contaminated only by Legionella pneumophila (L. pneumophila), samples contaminated only by Legionella non-pneumophila species (other Legionella spp.) and others contaminated by both species. Significant differences $(p=0.001)$, obtained with the statistical $\chi^{2}$ test, were found concerning the Legionella spp. distribution between hot and cold samples as follows: in hot-water samples, the main isolate belonged to L. pneumophila $123 / 190(64.7 \%)$, followed by samples with both species (L. pneumophila and other Legionella spp.) $41 / 190$ (21.6\%) and, finally, by $26 / 190$ (13.7\%) showing only the presence of other Legionella spp. In cold-water samples, we found the same trend, with 44/103 (42.7\%) of samples with L. pneumophila, 30/103 (29.1\%) contaminated by both species, and finally, 29/103 (28.1\%) with only other Legionella spp. The isolates of L. pneumophila were identified by an agglutination test as belonging to serogroups $1,3,4,6$, and 8 . The typing of Legionella non-pneumophila species by mip gene sequencing, indicated the presence of Legionella anisa (L. anisa), Legionella rubrilucens (L. rubrilucens), Legionella tauriniensis (L. tauriniensis), Legionella nautarum (L. nautarum), and Legionella steelei (L. steelei).

The study of Legionella isolates in terms of mean concentration \pm standard deviation ( $\log c f u / L \pm S D$ ) between hot- and cold-positive samples is presented in Table 2. Multiple comparisons were performed between isolates found in hot- and cold-water samples (horizontal lines), while the comparison between hot- and cold-water samples for each type of Legionella isolate is shown in the columns. High L. pneumophila concentrations were found in hot-water samples $(2.92 \pm 1.08 \mathrm{Log} \mathrm{cfu} / \mathrm{L})$ with significant difference compared to samples colonized by only other Legionella spp. $(p=0.03)$ and with respect to cold-water samples $(p=0.008)$. In cold-water samples, despite a high other Legionella spp. mean concentration $(2.47 \pm 0.72 \mathrm{Log} c f u / L)$, a significant difference was found only with respect to samples colonized by both species $(p=0.0046)$. 
Table 2. Legionella isolate mean concentration comparison in SHWOs: hot- vs. cold-water samples.

\begin{tabular}{|c|c|c|c|c|c|}
\hline Legionella Isolate & $\begin{array}{l}\text { Samples with Only } \\
\text { L. pneumophila } \\
\text { Mean } \pm \text { SD } \\
\text { (Log cfu/L) }\end{array}$ & $\begin{array}{l}\text { Samples with Only } \\
\text { Other Legionella spp. } \\
\text { Mean } \pm \text { SD } \\
\text { (Log cfu/L) }\end{array}$ & $\begin{array}{c}\text { Samples with } \\
\text { L. pneumophila } \\
\text { and Other Legionella spp. } \\
\text { Mean } \pm \text { SD } \\
(\text { Log cfu/L) } \\
\end{array}$ & $\begin{array}{r}\text { Legionella Is } \\
\text { Mean Compa } \\
\text { in Hot and Col } \\
\text { Mann-Whitne } \\
p \text {-Value }( \\
\end{array}$ & $\begin{array}{l}\text { ate } \\
\text { son } \\
\text { Water } \\
\text { Test } \\
\end{array}$ \\
\hline \multirow{3}{*}{$\begin{array}{c}\text { Hot } \\
\text { water } \\
\text { samples }\end{array}$} & \multirow{3}{*}{$2.92 \pm 1.08$} & \multirow{3}{*}{$2.31 \pm 0.66$} & \multirow{3}{*}{$3.13 \pm 0.85$} & $\begin{array}{c}\text { L. pneumophila } \\
\text { vs. } \\
\text { other Legionella spp. }\end{array}$ & $0.03 *$ \\
\hline & & & & $\begin{array}{c}\text { L. pneumophila } \\
\text { vs. } \\
\text { L. pneumophila and } \\
\text { other Legionella spp. }\end{array}$ & 0.40 \\
\hline & & & & $\begin{array}{l}\text { Other Legionella spp. } \\
\text { vs. } \\
\text { L. pneumophila and } \\
\text { other Legionella spp. }\end{array}$ & $0.00012 *$ \\
\hline \multirow{3}{*}{$\begin{array}{c}\text { Cold } \\
\text { water } \\
\text { samples }\end{array}$} & \multirow{3}{*}{$2.43 \pm 0.83$} & \multirow{3}{*}{$2.47 \pm 0.72$} & \multirow{3}{*}{$3.09 \pm 0.63$} & $\begin{array}{c}\text { L. pneumophila } \\
\text { vs. } \\
\text { other Legionella spp. }\end{array}$ & 1.00 \\
\hline & & & & $\begin{array}{c}\text { L. pneumophila } \\
\text { vs. } \\
\text { L. pneumophila and } \\
\text { Other Legionella spp. }\end{array}$ & $0.0012 *$ \\
\hline & & & & $\begin{array}{l}\text { Other Legionella spp. } \\
\text { vs. } \\
\text { L. pneumophila and } \\
\text { Other Legionella spp. }\end{array}$ & $0.0046^{*}$ \\
\hline $\begin{array}{c}\text { Legionella Isolate } \\
\text { Mean Comparison between } \\
\text { hot vs. cold samples } \\
\text { Mann-Whitney test } \\
p \text {-value }(p)\end{array}$ & $0.008 *$ & 0.4 & 0.7 & & \\
\hline
\end{tabular}

* Values are statistically significant at $p \leq 0.05$

\subsection{Legionella Contamination in Relation to Water Temperature}

Regarding the temperature measured between hot and cold samples, we found a range between 21.9-60.1 ${ }^{\circ} \mathrm{C}$ (mean value of $47.7^{\circ} \mathrm{C}$ ) and a range between $9.2-44.7^{\circ} \mathrm{C}$ (mean value of $19.1^{\circ} \mathrm{C}$ ) for hot and cold samples, respectively.

The Legionella contamination found considering all SHWOs samples was distributed in four ranges of temperature, which were linked to relevant considerations about the environment of Legionella as follows:

- the first range, called "I", represents the samples collocated at temperature values $<21{ }^{\circ} \mathrm{C}$. This temperature range corresponds to the standard one for drinking water for human consumption;

- the second range, called "II", was $21-45^{\circ} \mathrm{C}$, corresponding to the mixed water produced by outlets provided by TMVs;

- the third range, called "III", corresponds to the range between $45.1-49.6^{\circ} \mathrm{C}$. This range represents the setting temperature generally measured during environmental monitoring on hot-water system producers (e.g., boilers, electric tanks, heater-exchangers, and so on), other than the values suggested to reduce energy costs [20]; and

- the fourth range, called "IV", corresponds to temperature values $>49.6^{\circ} \mathrm{C}$. This is the optimal value suggested by the Italian Guidelines to control Legionella proliferation in water-distribution systems.

A multiple comparison was performed between each range by an ANOVA test, showing significant differences, as indicated in Table 3 with the ${ }^{*}$ ) symbol. 
Table 3. Mean Legionella concentration in relation to ranges of temperature measured (I, II, III, and IV).

\begin{tabular}{|c|c|c|c|c|c|c|}
\hline $\begin{array}{l}\text { Range of Temperature } \\
\left({ }^{\circ} \mathrm{C}\right)\end{array}$ & $\begin{array}{l}\text { Number of } \\
\text { Samples }\end{array}$ & $\begin{array}{c}\text { Number of } \\
\text { Positive Samples } \\
(\%)\end{array}$ & $\begin{array}{l}\text { Mean Legionella } \\
\text { Concentration } \\
\text { (Log cfu/L) }\end{array}$ & $\begin{array}{l}\text { 95\% Confidence } \\
\text { Interval } \\
\text { (CI) }\end{array}$ & $\begin{array}{l}\text { Range of } \\
\text { Temperature } \\
\text { Comparison }\end{array}$ & $\begin{array}{c}\text { ANOVA } \\
\text { Test } \\
p \text {-Value } \\
(p)\end{array}$ \\
\hline$<21$ & 168 & $\begin{array}{c}54 \\
(32.1)\end{array}$ & 1.78 & $1.65-1.91$ & $\begin{array}{l}\text { vs. II } \\
\text { vs. III } \\
\text { vs. IV }\end{array}$ & $\begin{array}{l}0.464 \\
0.002^{*} \\
1.000\end{array}$ \\
\hline $21-45$ & 157 & $\begin{array}{c}59 \\
(37.6)\end{array}$ & 1.98 & $1.81-2.15$ & $\begin{array}{l}\text { vs. I } \\
\text { vs. III } \\
\text { vs. IV }\end{array}$ & $\begin{array}{c}0.464 \\
0.474 \\
0.012 *\end{array}$ \\
\hline $45.1-49.6$ & 172 & $\begin{array}{c}81 \\
(47.1)\end{array}$ & 2.17 & $2.00-2.34$ & $\begin{array}{l}\text { vs. I } \\
\text { vs. II } \\
\text { vs. IV }\end{array}$ & $\begin{array}{c}0.002 * \\
0.474 \\
0.001 * \\
\end{array}$ \\
\hline$>49.6$ & 172 & $\begin{array}{c}40 \\
(23.2)\end{array}$ & 1.64 & $1.51-1.78$ & $\begin{array}{c}\text { vs. I } \\
\text { vs. II } \\
\text { vs. III }\end{array}$ & $\begin{array}{c}1.000 \\
0.012^{*} \\
0.001 *\end{array}$ \\
\hline
\end{tabular}

* Values are statistically significant at $p \leq 0.05$.

The contamination of samples in relation to the temperature measured during the sampling reveals that the main Legionella positive samples (47.1\%) were in the third range (III), which was also the main contaminated source in terms of Legionella mean concentration $(2.17 \mathrm{Log} \mathrm{cfu} / \mathrm{L})$. By contrast, the lowest percentage of positive samples $(23.2 \%)$ and mean concentration $(1.64 \mathrm{Log} \mathrm{cfu} / \mathrm{L})$ were found in the fourth range (IV).

In Figure 2, the distribution of mean Legionella concentration in relation to temperature values measured is represented, with hot and cold samples separately considered, in ranges between 21.9-60.1 ${ }^{\circ} \mathrm{C}$ (mean value of $47.7^{\circ} \mathrm{C}$ ) and between $9.2-44.7^{\circ} \mathrm{C}$ (mean value of $19.1^{\circ} \mathrm{C}$ ).

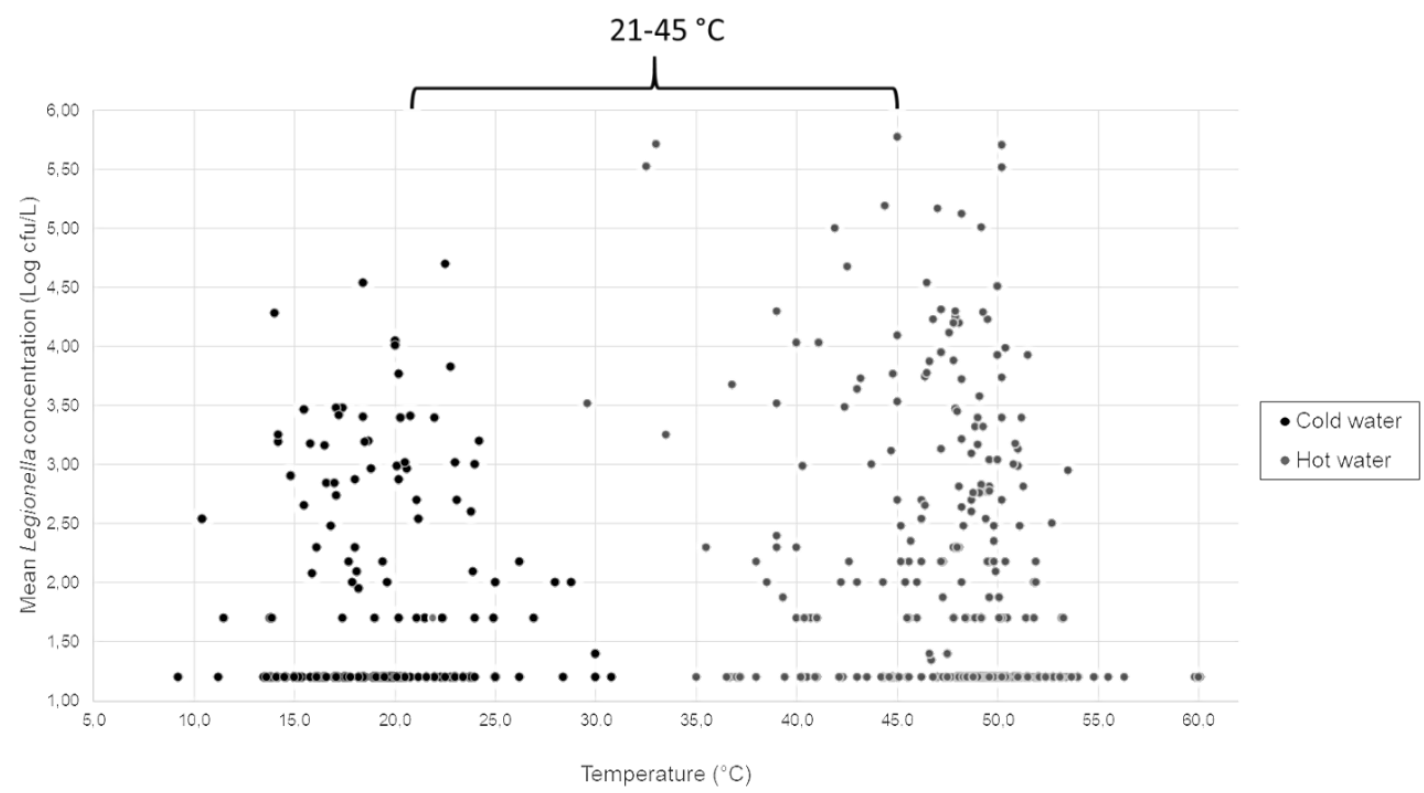

Figure 2. Mean Legionella concentration distribution in relation to water sample temperatures measured $\left({ }^{\circ} \mathrm{C}\right)$.

An analysis of the results considering only samples in the range of $21-45^{\circ} \mathrm{C}$ (e.g., the range for SHWO mixed water) showed 98/427 (23.0\%) and 81/242 (33.5\%) contaminated hot- and cold-water samples, with mean concentrations of $2.12 \pm 1.22 \mathrm{Log} c f u / L$ and $1.87 \pm 0.92 \mathrm{Log}$ cfu/L, respectively.

Considering only Legionella-positive samples, we found 52/98 (53.0\%) in hot water-respectively $39 / 81$ (48.1\%) in cold water-with mean Legionella concentration higher in hot $(2.94 \pm 1.17 \mathrm{Log} \mathrm{cfu} / \mathrm{L})$ than cold samples $(2.60 \pm 0.87 \mathrm{Log} \mathrm{cfu} / \mathrm{L})$. The nonsignificant difference was found using the Mann-Whitney test $(p=0.22)$. 


\subsection{Legionella Contamination before and after the SHWO Replacement}

In three hospitals (called 1, 8, and 11), following renovation works, replacement of sensor-activated faucets with TMVs by clinical valves without TMVs was carried out. The reassessment of Legionella contamination on the same SHWOs after replacement permitted us to observe changes in the Legionella concentration. Analyzing the contamination found in 110 of 669 total samples collected in these hospitals, we compared the contamination before $(n=55)$ and after $(n=55)$ replacement. As shown in Table 4 , we observed a significant decrease in terms of Legionella contamination $(p=0.001)$ with the same significant trend in each hospital, other than with an increase of hot-water temperature and a consequent decrease of Legionella levels.

Table 4. Mean Legionella concentration in three hospitals before and after the replacement of sensor-activated faucets with Thermostatic Mixer Valves (TMVs).

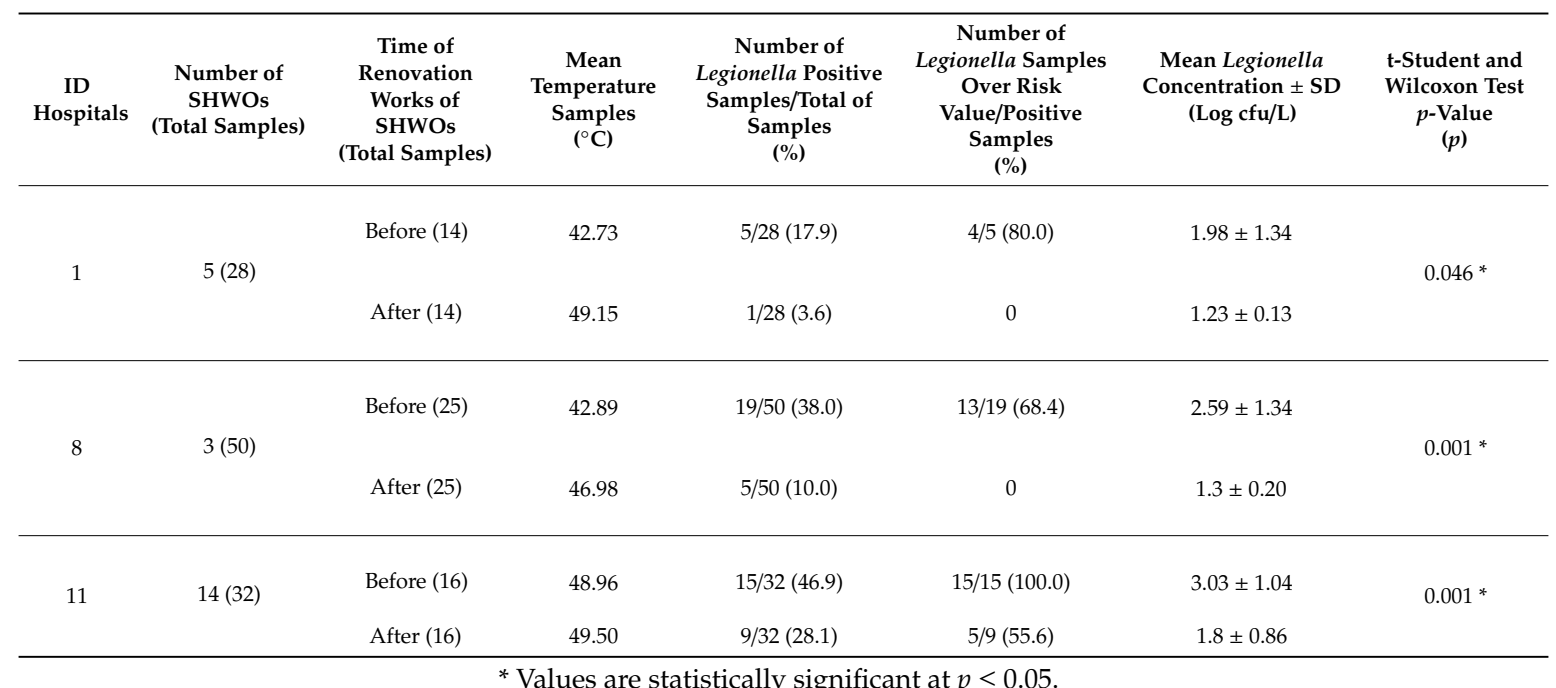

\subsection{P. aeruginosa Contamination in SHWOs}

The data about P. aeruginosa contamination indicated that 27/669 (4.0\%) samples were contaminated. Considering the contamination in relation to hot- and cold-water circuits, we found a higher contamination in cold-water samples compared to hot-water samples: 22/242 (9.0\%) and 5/427 (1.2\%), respectively. However, the low number of positive samples did not permit us to find a statistical correlation between the data analyzed $(p=0.65)$.

\subsection{Disinfectant Residue Analysis}

Concerning the disinfectant residue measured, the mean concentration of hydrogen peroxide $\left(\mathrm{H}_{2} \mathrm{O}_{2}\right)$ component was about $2.5 \mathrm{mg} / \mathrm{L}$ and $10 \mathrm{mg} / \mathrm{L}$ in cold- and hot-water samples, respectively. Although only the hot water network is treated with hydrogen peroxide/ $\mathrm{Ag}^{+}\left(\mathrm{H}_{2} \mathrm{O}_{2} / \mathrm{Ag}^{+}\right)$, we found the presence of disinfectant residue in all cold-water samples, with a range between $0.5-5 \mathrm{mg} / \mathrm{L}$.

\section{Discussion}

The prevention of HAIs is an important problem, particularly in high-risk patient care. The risk of infections has been linked to interactions between pathogens and hosts which involves the number of microorganisms, their virulence factors, and the host's immune defenses [21]. To reduce the impact on human health as well as to avoid economic, legal, and political issues, particular attention must be directed to a hospital's hygiene and environment. This aim can arise only through the development of a risk assessment plan which is linked to knowledge of the hospital and patient characteristics, the health-care procedures already in place and to be improved, and the hospital environment where 
patients and HCS may be in contact with microorganisms through the air, water, and contaminated surfaces $[6,22,23]$.

The new revision of the European Drinking Water Directive, such as the WHO Guidelines for Drinking Water Quality, suggests the approach of the Water Safety Plan to identify the main pathogens involved in waterborne diseases, to understand their pathogenic pathways, and to contain their impact on public health [24-28]. Legionella and P. aeruginosa are two of the main waterborne pathogens involved in hospital environments associated with nosocomial infections $[6,29,30]$.

This study reports knowledge acquired during a Legionella environmental surveillance program performed in hospitals, where high Legionella levels were detected in SHWOs with TMVs, some of them with concentrations over the risk level ( $>2 \log \mathrm{cfu} / \mathrm{L})$, suggesting their critical role in bacterial growth and HAI risk. It has been well documented that temperature is a key factor in microbial growth and that, in particular, the mixing of hot and cold water creates an optimal temperature for bacterial environment, which can occur in SHWOs [8,23,31,32].

To analyze the contamination found in SHWOs, hot- and cold-water data sets were separately studied in terms of percentage of positive samples, level of contamination, and Legionella isolates distribution, including temperature as a possible determining factor for data fluctuations in the microbial parameters analyzed.

The results showed a similar percentage of hot- and cold-water samples $(44.5 \%$ and $42.6 \%$, respectively) contaminated by Legionella, with the same trend regarding samples over the Legionella risk level (73.7\% hot vs. $68.0 \%$ cold). A nonsignificant difference in terms of Legionella contamination between hot and cold samples $(p=0.34)$ demonstrates how hot- and cold-water circuits are not separate with continuous mixing between two pipelines, creating an environment capable of supporting Legionella growth.

These results are supported by the residues of $\mathrm{H}_{2} \mathrm{O}_{2}$ disinfectant found also in cold-water samples. This disinfectant introduced in hospitals is injected only into the return line of the hot-water distribution system, and generally, when the two main distribution systems (e.g., hot and cold) are well separated, the cold water is expected to be free of disinfectant residues. This observation can be attributed to damage on the TMV cartridge because, during cold-water sampling, although the TMVs were deactivated, we found disinfectant residues in all samples. Moreover, damage in the TMV device was supported by the temperatures measured, which revealed a decrease in hot-water values and an increase in cold-water values, as demonstrated by the large ranges of temperature: $21.9-60.1{ }^{\circ} \mathrm{C}$ and $9.2-44.7^{\circ} \mathrm{C}$ for hot and cold, respectively.

Considering the distribution of Legionella isolates, a significant difference was found between hot- and cold-water-positive samples $(p=0.001)$, showing that the characteristics of the mixed water produced are able to influence the distribution of isolates. According to knowledge about Legionella ecology and epidemiological data, the main positive samples found in hot and cold water $(64.7 \%$ vs. $42.7 \%$ ) belonged to L. pneumophila (serogroups $1,3,4,6$, and 8 ). In a low percentage of hotand cold-water samples, we found isolates belonging to Legionella non-pneumophila species (L. anisa, L. rubrilucens, L. tauriniensis, L. nautarum, and L. steelei), with high values in cold water compared to hot water $(28.1 \%$ vs. $13.7 \%)$. The same differences were found between cold and hot samples regarding the percentage of positive samples contaminated by both species (L. pneumophila and other Legionella spp.).

These data required supplementary analysis regarding the level of contamination found inside each distribution system and between them. In hot-water samples, we found a higher Legionella contamination in samples contaminated by both isolates, with a significant difference with respect to the level of contamination found in samples with only other Legionella spp. $(p=0.00012)$. A significant difference was, therefore, found in terms of the level of contamination between L. pneumophila and other Legionella spp. $(p=0.03)$.

In cold-water samples, we observed a different trend, with high samples contaminated by both species showing significant differences with respect to samples having only L. pneumophila $(p=0.0012)$ and samples contaminated by only other Legionella spp. $(p=0.0046)$. 
Considering the comparison of mean concentration found for each isolate between hot versus cold samples, a significant difference was found only for L. pneumophila $(p=0.008)$.

Relevant information comes from these results regarding the ecology of isolates in water distribution systems.

Legionella lives in a water environment, with optimal growth in warm environments. Therefore, the abundance of L. pneumophila in hot-water samples found was in line with data about the high incidence of this species in human disease. In hot-water environments, there is likely a selective pressure of L. pneumophila on Legionella non-pneumophila species, which is suppressed in cold-water distribution systems, as demonstrated by the high number of samples with both species when the water temperature was mixed. Our hypothesis is also based on observations done during Legionella culture, where we generally find a lower Legionella non-pneumophila species isolation rate, due to their slow growth and late detection after 10-15 days of incubation when L. pneumophila is more abundant. When the culture technique was conducted up to 10 days, some of these species were missing and, consequently, underestimated; by contrast, an extension of culture timing permits their detection.

The poor awareness of these species and their underestimation is also associated to the low rate of clinical isolation, to their low correlation with human disease, and to the non-detection by diagnostic techniques (e.g., antigenic urinary tests) [33,34].

Another important point that can explain the high presence of Legionella non-pneumophila species in cold water is related to the disinfection treatment that often, as seen in this study, is performed on the hot-water circuit, leaving the cold-water distribution system without any type of control (monitoring by culture, temperature measures, flushing, and disinfectant residues measures). This represents a reservoir for other Legionella species. The absence of disinfectant or low levels of disinfectant residues measured usually require high temperatures for their activation and are unable to control their growth.

These results were also confirmed by our previous data [35] regarding the ability of Legionella to colonize and increase its concentration in cold-water distribution systems, inducing a change of cold water microflora; during renovation works, pipeline, TMV, and faucet damage; or when rapid breakdown of hot temperatures occurs. The presence of a high percentage of positive samples with high Legionella concentration contaminated by both species in both distribution systems confirms that SHWOs with mixed water develop an environment favorable to Legionella growth.

The high contamination of SHWOs are therefore supported by a wide fluctuation of temperatures found in samples: both low and high temperatures are able to favor bacteria growth. The analysis of contamination levels with respect to temperatures was analyzed by dividing the temperature values measured between four ranges, each of them associated to the ecology of Legionella.

The possibility to maintain separation between cold- and hot-water pipelines is one of the strategies suggested by National and European directives in order to contain the proliferation of bacteria. Our data demonstrated an inverse correlation between the temperature and bacteria load: at higher temperatures $\left(>49.6^{\circ} \mathrm{C}\right)$, a lower Legionella mean concentration (1.64 Log cfu/L) was observed, according with the directive's suggestions about the value of $>50{ }^{\circ} \mathrm{C}$ being able to perform complete control of the level of Legionella [12].

The results obtained inside the II and III ranges of temperature $\left(21-45{ }^{\circ} \mathrm{C}\right.$ and $45.1-49.6{ }^{\circ} \mathrm{C}$, respectively) showed approximately the same Legionella concentrations with a nonsignificant difference inside these ranges $(p=0.474)$. These data confirm that samples with temperature close to the optimum Legionella growth range $\left(25-42^{\circ} \mathrm{C}\right)$ are more contaminated and that an increase of temperature $\left(>49.6^{\circ} \mathrm{C}\right)$ leads to control of the Legionella proliferation (II vs. IV, $p=0.012$; III vs. IV, $p=0.001$ ) [36].

The contamination in SHWOs and the wide range of temperatures found can be explained, moreover, by taking into account the SHWO technology provided by hospitals. All of them are characterized by the presence of magnetic valves, which are the principal part of electronic/non-touch/sensor tap systems. Cold and hot water from the junctions of the central water pipeline system are mixed to provide an acceptable and comfortable setting temperature, generally, around $36^{\circ} \mathrm{C}$. The magnetic valves in the cartridge are made of material membranes-for example, 
made of rubber, plastic, or Polyvinyl Chloride (PVC)—which are very hard to disinfect and easily enhance bacterial growth and biofilm development, which can become a protective envelope against biocides and disinfectants. Furthermore, in these tap systems, flushing procedures are forbidden by the presence of a photocell system, leading to low water pressure and flow [18]. These considerations were supported by data about positive samples located in the range of the TMVs' working temperature $\left(21-45^{\circ} \mathrm{C}\right)$, which is very close to the temperature associated with optimal Legionella growth, where we did not find a difference between hot and cold samples.

Our hypothesis is strengthened furthermore by the observation that, in three hospitals which implemented a substitution program from sensor-activated faucets with TMVs to manual clinical valves without TMVs, an increase of mean temperature was measured, corresponding to a significant reduction trend in Legionella concentration levels.

As concerning $P$. aeruginosa SHWO contamination, the lower presence of positive samples coming from the eleven hospitals suggests the general good performance of disinfection procedures applied by hospital staff on faucets. The choice of tapware provided by faucet aerators guarantees low pressure without an internal thread, and descaling and disinfection procedures are applied weekly, permitting to avoid bacterial growth on outlets and preventing biofilm development [32].

The data regarding the higher $P$. aeruginosa contamination in cold-water samples can be explained by the same consideration as for sensor-activated faucets in Legionella contamination due to the sharing of these bacteria in the same habitat.

These findings led to the following considerations:

- the implementation of environmental monitoring in the cold-water distribution system, where Legionella surveillance is often missing, helps to explain the lower hot-water temperature sometimes observed also in hot water, which is often associated to damage in the mixing water system (e.g., in TMVs, levers, or faucets);

- the replacement of broken devices avoids the necessity of use of disinfection treatment in the whole distribution system, which can enhance bacterial resistance according to Berjeaud et al. [37]; and

- the continuous mixing between hot and cold water produced by TMVs leads to a mixture regarding the distribution of Legionella isolates in hot- and cold-water systems, as suggested by our data, developing a potential source of infection in cold water.

\section{Materials and Methods}

The eleven hospitals of this study, numbered 1 to 11, were involved in a Legionella environmental surveillance program from 2013 to 2019. After the introduction of last version of the Italian Guidelines in 2015, the 11 hospitals developed a risk assessment plan for Legionella control, considering the locations of buildings, their types of patients, and the water distribution system characteristics. All hospitals were supplied by municipal water that, after softener treatment, was heated by a heat-exchanger along with a hot-water return line.

All hospitals performed a six-month plan of Legionella environmental monitoring and active surveillance to control nosocomial Legionella infection by urinary-antigen test. Therefore, a complete program of maintenance procedures by measuring and recording temperatures, flushing outlet points, continuous disinfection of the system by $\mathrm{H}_{2} \mathrm{O}_{2} / \mathrm{Ag}^{+}$, and a fortnightly plan regarding aerator disinfection and/or replacement was undertaken.

During environmental monitoring, we found a higher Legionella concentration in SHWOs with respect to other hospital outlets involved in monitoring, indicating the necessity of a supplementary investigation.

In Table 5, the number of SHWOs $(n=52)$ in each hospital is reported, all of them equipped with sensor-activated faucets with TMVs (Figure 3). The main distribution system supplied hot-water outlets in a temperature range between $40-50{ }^{\circ} \mathrm{C}$, while the cold-water outlets showed a temperature range of $15-20^{\circ} \mathrm{C}$. In SHWOs, the presence of TMVs produced a continuous mixed water at a set temperature around $36^{\circ} \mathrm{C}$. 
Table 5. Number of SHWOs/hospitals.

\begin{tabular}{cccccccccccc}
\hline Number & \multicolumn{10}{c}{ ID Hospitals } \\
\cline { 2 - 12 } $\begin{array}{c}\text { of } \\
\text { SHWOs }\end{array}$ & 1 & 2 & 3 & 4 & 5 & 6 & 7 & 8 & 9 & 10 & 11 \\
$(\boldsymbol{n}=\mathbf{5 2})$ & 5 & 5 & 5 & 1 & 6 & 2 & 2 & 3 & 4 & 5 & 14 \\
\hline
\end{tabular}

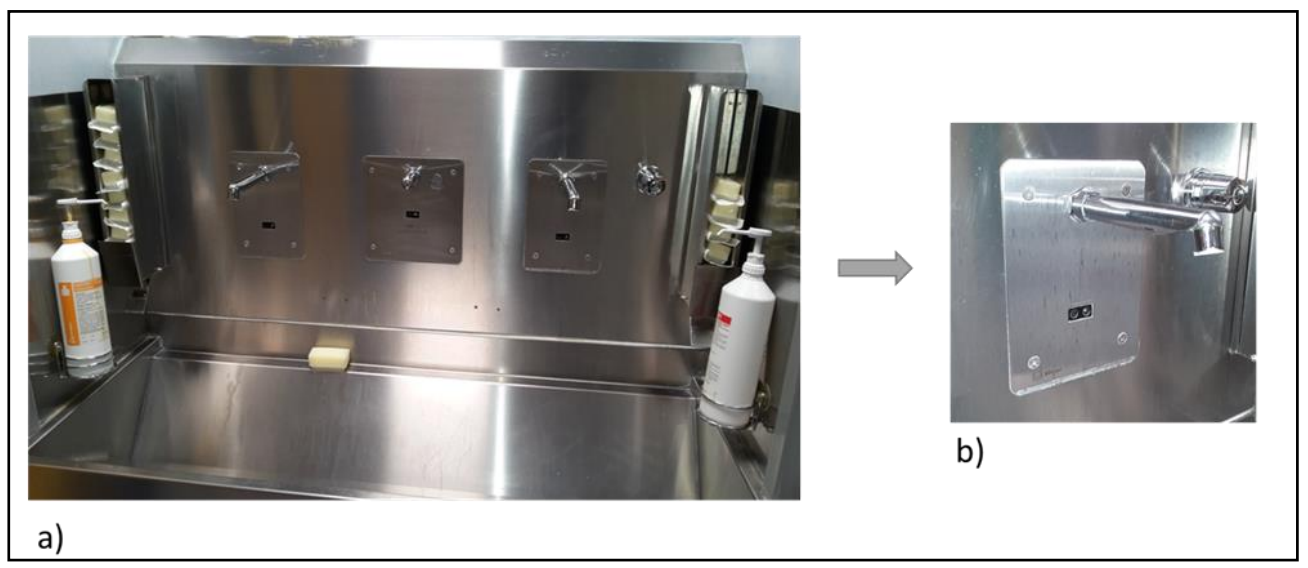

Figure 3. SHWOs with sensor-activated faucets and TMVs (a) and a sensor-activated faucet (b).

During the study, eight hospitals had not implemented any replacement in SHWOs; however, three hospitals $(1,8$, and 11) implemented a substitution program for their surgical hand preparation points regarding the faucet apparatuses: sensor-activated faucets with TMVs were removed and substituted with elbow-operated manual faucets without TMVs (Figure 4).

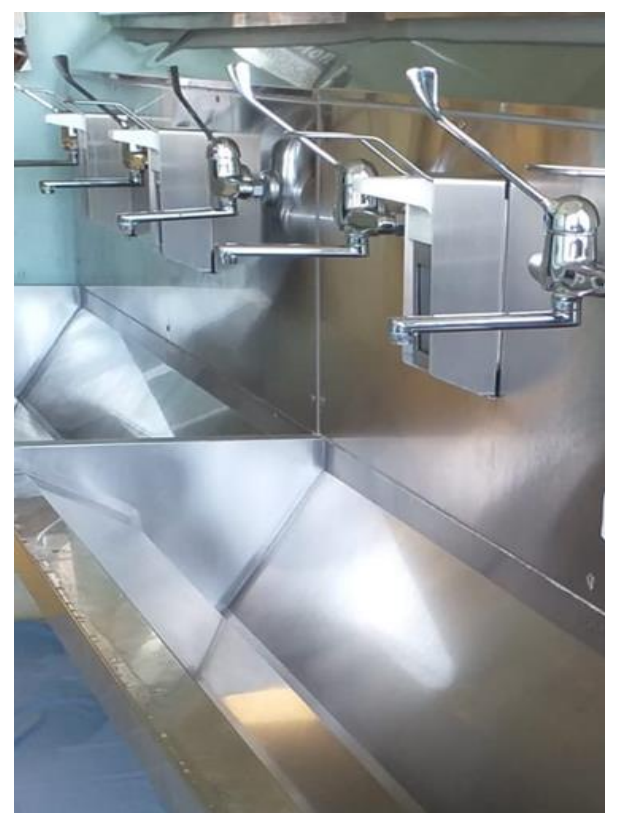

Figure 4. SHWOs with elbow-operated manual faucets without TMVs.

The environmental surveillance program consisted of Legionella and P. aeruginosa monitoring, according to the risk assessment plans provided by hospital healthcare directives.

The hot-water circuit in all hospitals was treated by $\mathrm{H}_{2} \mathrm{O}_{2} / \mathrm{Ag}^{+}$disinfectant, which was added by a pump proportionally to the volume of cold water supply at a concentration around $50 \mathrm{mg} / \mathrm{L}$ in order to allow a residue at outlets between $10-20 \mathrm{mg} / \mathrm{L}$, following manufacturer's instructions. 
To assess the complete monitoring of water microbiological quality supplied by SHWOs and to evaluate differences in terms of contamination between hot- and cold-water distribution systems, both circuits were sampled.

For the three hospitals that implemented a substitution program with manual clinical valves without TMVs, the data of cold-water samples were not available, as the risk assessment plan after replacement involved only hot SHWO samples; therefore, comparison in terms of Legionella contamination before and after the substitution program was considered only in hot-water circuits.

\subsection{SHWO Sampling}

According to the Italian Guidelines for the Prevention and Control of Legionellosis [12], analysis of Legionella contamination was performed by collecting two liters of cold and hot SHWO samples. In particular, in order to determine the quality in the main distribution system, post-flushing sampling was applied, which consisted of removing the filter or faucets, disinfection of taps with ethanol $(70 \%)$, open taps, flushing for $2 \mathrm{~min}$, and collection of cold before hot samples [38]. For cold samples, the TMVs were deactivated; by contrast, TMVs were reactivated to collect hot samples at the setting temperature for SHWOs $\left(36^{\circ} \mathrm{C}\right)$.

From the 52 SHWOs, 669 samples were collected (427 hot and 242 cold), where two liters of water were sampled using 1-liter sterile polytetrafluoroethylene (PTFE) bottles containing sodium thiosulphate $(20 \mathrm{mg} / \mathrm{L})[38,39]$.

The samples were processed by a membrane-filtration technique using polyethersulfone membrane filters with a porosity of $0.22 \mu \mathrm{m}$ (Sartorius, Bedford, MA, USA), according to the International Standard Organization (ISO) 11731:2017 procedure [40].

\subsection{Legionella and P. aeruginosa Culture and Typing}

The Legionella culture was performed on Glycine-Polymyxin B-Vancomycin-Cycloheximide (GVPC) plates (Thermo Fisher Diagnostic, Basingstoke, UK) and subsequently incubated at $36 \pm 1{ }^{\circ} \mathrm{C}$ with $2.5 \% \mathrm{CO}_{2}$. Legionella growth was evaluated every 2 days for a total of 15 days of culture.

After the incubation period, the colonies with morphologies associated to the Legionella genus were enumerated and five suspected colonies for each morphology, as indicated by ISO 11731:2017, were subcultured on Buffered Charcoal Yeast Extract (BCYE) agar with L-cysteine (cys+) and without L-cysteine (cys-) as supplement, which is a selective media used for Legionella isolation. The positive Legionella colonies were those that grew on Legionella BCYE cys+ agar but failed to grow on Legionella BCYE cys- agar.

The isolates grown on BCYE cys+ were serologically typed by an agglutination test (Legionella latex test kit, Thermo Fisher Diagnostic, Basingstoke, UK). The isolates identified as L. pneumophila were then processed for serogroup identification by polyclonal latex reagents (Biolife, Milan, Italy).

Colonies identified by the agglutination test as belonging to Legionella non-pneumophila species were subsequently analyzed by mip gene sequencing and by Polymerase Chain Reaction (PCR) using degenerate primers (as described by Ratcliff et al. [41]) and modified by M13 tailing to avoid noise in the DNA sequence [42]. Gene amplification was carried out in a $50-\mu \mathrm{L}$ reaction containing DreamTaq Green PCR Master Mix 2× (Thermo Fisher Diagnostic) and 40 picomoles of each primer; 100 nanograms of DNA extracted from the presumptive colonies of Legionella was added as a template. The same amounts of DNA from L. pneumophila type strain EUL00137, provided by the European Working Group for Legionella Infections (EWGLI) [43], and fetal bovine serum were used as positive and negative controls, respectively.

Following purification, DNA was sequenced using BigDye Chemistry and analyzed on an ABI PRISM 3100 Genetic Analyzer (Applied Biosystems, Foster City, CA, USA). Specifically, mip amplicons (661-715 base pairs) were sequenced using M13 forward and reverse primers (mip-595R-M13R caggaaacagctatgaccCATATGCAAGACCTGAGGGAAC; mip-74F-M13F tgtaaaacgacggccagtGCTGCAACCGATGCCAC) to obtain complete coverage of the sequenced region 
of interest. Raw sequencing data were assembled using the CLC Main Workbench 7.6.4 software (QIAGEN, Redwood City, CA, USA). The sequences were compared with sequences deposited in the Legionella mip gene sequence database using a similarity analysis tool. Identification on the species level was done based on $\geq 98 \%$ similarity to a sequence in the database [44].

The results regarding Legionella contamination in the samples were expressed as colony formant unit (cfu) per liter (cfu/L). According to ISO 11731:2017, a negative result (absence of bacteria growth) was expressed as the lower limit of detection, that is, $<50 \mathrm{cfu} / \mathrm{L}$ [40].

The same samples $(n=669)$ were analyzed to quantify the presence of $P$. aeruginosa due to its role in biofilm formation and to its capacity to inhibit Legionella growth during isolation culture, producing inaccurate results [45]. The analysis was performed on a volume of $100 \mathrm{~mL}$ of hot and cold samples, filtered using a cellulose nitrate membrane filter with a $0.45-\mu \mathrm{m}$ pore size (Sartorius, Bedford, MA, USA), according to UNI EN ISO 16266:2008 [46,47].

The membrane was seeded on Pseudomonas-selective agar plate (PSA, Biolife, Milan, Italy) and incubated for $48 \mathrm{~h}$ in $36^{\circ} \mathrm{C}$ incubators. Colonies that showed green-blue fluorescence when placed under a Wood's lamp (ultraviolet light at $365 \mathrm{~nm}$ ) were subcultured on Nutrient agar (NA, Biolife, Milan, Italy) for 18-24 h. Subsequently, the colonies were identified biochemically as P. aeruginosa by indole, oxidase reaction tests, and BBL Crystal Enteric/Non Fermenter ID Kit (Becton Dickinson Systems, Cockeysville, MD, USA), according to the manufacturer's instructions.

The results are expressed in terms of $\mathrm{cfu} / 100 \mathrm{~mL}$.

\subsection{Physical and Chemical Analyses}

The physical and chemical parameters-the temperature of the water samples as well as the disinfectant residues at $\mathrm{SHWOs-were} \mathrm{measured} \mathrm{during} \mathrm{the} \mathrm{collection} \mathrm{of} \mathrm{samples.}$

The temperature $\left({ }^{\circ} \mathrm{C}\right)(\mathrm{T})$ was measured by a conductivity meter coupled with a thermistor probe (Temp 6 basic for probe Pt100 RTD from -50 to $+199{ }^{\circ} \mathrm{C}$; Thermo Fisher Scientific Inc., Eutech Instruments Pte Ltd., Singapore). An on-site commercial kit for the residual hydrogen peroxide component of $\mathrm{H}_{2} \mathrm{O}_{2} / \mathrm{Ag}^{+}(\mathrm{mg} / \mathrm{L})$ was used. The kit uses a colorimetric test based on peroxidase activity to transfer peroxide oxygen to an organic redox indicator, which produces a blue oxidation product.

The hydrogen peroxide concentration was measured semiquantitatively by visual comparison of the result seen on the reaction zone of the test strip with the fields on a color scale in a range of $0.5-25 \mathrm{mg} / \mathrm{L} \mathrm{H}_{2} \mathrm{O}_{2}$.

\subsection{Statistical Analysis}

The Legionella concentration data were converted into $\log _{10} \mathrm{cfu} / \mathrm{L}(\log \mathrm{cfu} / \mathrm{L})$ to normalize the non normal distributions. According to the Italian Guidelines for Legionella, the detection limit corresponding to $50 \mathrm{cfu} / \mathrm{L}(1.7 \mathrm{Log} \mathrm{cfu} / \mathrm{L})$ was used; by contrast, the risk value, $>100 \mathrm{cfu} / \mathrm{L}$, was expressed as $>2 \log \mathrm{cfu} / \mathrm{L}$.

To compare data of hot- and cold-water Legionella concentrations, the Mann-Whitney test was used (Table 1).

The distribution of different Legionella isolates between hot and cold positive samples was studied by chi-squared test $\left(\chi^{2}\right)$. Therefore, the differences in Legionella isolate concentrations in hot- or cold-water samples were studied by the Kruskal-Wallis test: the significant data found were then also analyzed by the Mann-Whitney test (Table 2).

Multiple comparisons between Legionella concentrations and the four ranges of temperature measured were performed by using the ANOVA test (Table 3).

Regarding the three hospitals that implemented the replacement program (e.g., with elbow-operated clinical valves without TMVs), the data analysis to compare Legionella levels before and after replacement was performed by parametric $t$-Student test when considering a number of values $n>30$ and by nonparametric Wilcoxon test for $n<30$ (Table 4 ). 
The P. aeruginosa results were converted into Log cfu $/ 100 \mathrm{~mL}$. The contamination found was studied by Mann-Whitney test to compare hot- and cold-water samples.

Statistical analyses were performed using the SPSS software for Windows version 23 (IBM SPSS, Inc., Chicago, IL, USA).

The data were considered significant for $p$ values $(p) \leq 0.05$.

\section{Conclusions}

In conclusion, sensor-activated faucets with TMVs are generally more contaminated than clinical valves without thermostatic mixers. This allows us to conclude that the technologies typically chosen by a hospital do not correspond with the water microbiological environment that can develop in the SHWOs. The microbial interaction with the selected technologies, pipeline and faucet materials, and chemical-physical water characteristics result in an environment that, in semi-critical and critical areas, can lead to serious risks for patients, hospital staff, and stakeholders involved in maintenance procedures. The limit of this study is the lack of data on cold water after the replacement program developed by three hospitals due to there being no cold-water monitoring in the risk assessment plan, to poor knowledge, and to cost-containment demands.

The authors wish to encourage infection control teams to evaluate the use of non-touch fittings in hospitals, especially when installed in high-risk areas, and wish to promote water microbial monitoring in both hot- and cold-water distribution systems according to a water safety plan that can guide the hospital's choices based on epidemiological data, technological knowledge, and applied maintenance procedures.

Author Contributions: S.C. and M.M. conceived and designed the experiments and wrote the paper. L.G., M.R.P., and J.L. performed sample collection and the experiments. S.S. and A.D. performed the statistical analyses. All authors have read and agreed to the published version of the manuscript.

Funding: This work was partially supported by a research grant (RFO 2018) from the University of Bologna, Italy.

Acknowledgments: The authors would like to thank the GVM Engineering staff for technical assistance and Graziella Ciani for microbiological analyses.

Conflicts of Interest: The authors declare no conflict of interest.

\section{References}

1. Khan, H.A.; Baig, F.K.; Mehboob, R. Nosocomial infections: Epidemiology, prevention, control and surveillance. Asian Pac. J. Trop. Biomed. 2017, 7, 478-482. [CrossRef]

2. Antonioli, P.; Bolognesi, N.; Valpiani, G.; Morotti, C.; Bernardini, D.; Bravi, F.; Di Ruscio, E.; Stefanati, A.; Gabutti, G. A 2-year point-prevalence surveillance of healthcare-associated infections and antimicrobial use in Ferrara University Hospital, Italy. BMC Infect. Dis. 2020, 20, 75. [CrossRef] [PubMed]

3. Istituto Superiore di Sanità, Italia. Infezioni correlate all'assistenza aspetti epidemiologici. Available online: https://www.epicentro.iss.it/infezioni-correlate/epidemiologia (accessed on 15 April 2020).

4. Squier, C.; Yu, V.L.; Stout, J.E. Waterborn nosocomial infections. Curr. Infect. Dis. Rep. 2000, 2, 490-496. [CrossRef] [PubMed]

5. Spagnolo, A.M.; Cristina, M.L.; Casini, B.; Perdelli, F. Legionella pneumophila in healthcare facilities. Rev. Med. Microbiol. 2013, 24, 70-80. [CrossRef]

6. Anaissie, E.J.; Penzak, S.R.; Dignani, M.C. The hospital water supply as a source of nosocomial infections: A plea for action. Arch. Intern. Med. 2002, 162, 1483-1492. [CrossRef] [PubMed]

7. Guidelines for Environmental Infection Control in Health-Care Facilities: Recommendations of CDC and the Healthcare Infection Control Practices Advisory Committee (HICPAC), 2003. MMWR Recomm. Rep. 52(RR-10), 1-42. Available online: https://www.cdc.gov/mmwr/preview/mmwrhtml/rr5210a1.htm (accessed on 12 February 2020).

8. Cristina, M.L.; Spagnolo, A.M.; Casini, B.; Baggiani, A.; Del Giudice, P.; Brusaferro, S.; Poscia, A.; Moscato, U.; Perdelli, F.; Orlando, P. The impact of aerators on water contamination by emerging Gram-negative opportunists in at-risk hospital departments. Infect. Control. Hosp. Epidemiol. 2014, 35, 122-129. [CrossRef] 
9. Fields, B.S.; Benson, R.F.; Besser, R.E. Legionella and Legionnaires' disease: 25 years of investigation. Clin. Microbiol. Rev. 2002, 15, 506-526. [CrossRef]

10. Rota, M.C.; Caporali, M.G.; Bella, A.; Scaturro, M.; Giannitelli, S.; Ricci, M.L. Rapporto annuale sulla legionellosi in Italia nel 2018. Notiziario Ist. Super Sanità 2019, 32 (11). Available online: http://www. legionellaonline.it/Not\%20ISS\%20nov\%202019.pdf (accessed on 3 February 2020).

11. Laganà, P.; Facciolà, A.; Palermo, R.; Delia, S. Environmental Surveillance of Legionellosis within an Italian University Hospital-Results of 15 Years of Analysis. Int. J. Environ. Res. Public Health 2019, 16, 1103. [CrossRef]

12. Italian Health Ministry. Guidelines for Prevention and Control of Legionellosis. Approvate in Conferenza Stato-Regioni Seduta Del 7 Maggio 2015. Italy, 2015. Available online: http://www.salute.gov.it/imgs/C_17_ pubblicazioni_2362_allegato.pdf (accessed on 2 March 2020).

13. Mitchell, A.; Spencer, M.; Edmiston, C., Jr. Role of healthcare apparel and other healthcare textiles in the transmission of pathogens: A review of the literature. J. Hosp. Infect. 2015, 90, 285-292. [CrossRef]

14. World Health Organization. Guidelines on Hand Hygiene in Health Care (Advanced Draft). 2006. Available online: https://www.who.int/patientsafety/information_centre/Last_April_versionHH_Guidelines\%5B3\% 5D.pdf (accessed on 12 February 2020).

15. World Health Organization. Guidelines on Hand Hygiene in Health Care: First Global Patient Safety Challenge Clean Care is Safer Care. 2009. Available online: https:/apps.who.int/iris/bitstream/handle/10665/ 44102/9789241597906_eng.pdf?sequence=1 (accessed on 12 February 2020).

16. Ellingson, K.; Haas, J.P.; Aiello, A.E.; Kusek, L.; Maragakis, L.L.; Olmsted, R.N.; Perencevich, E.; Polgreen, P.M.; Schweizer, M.L.; Trexler, P.; et al. Strategies to Prevent Healthcare-Associated Infections through Hand Hygiene. Infect. Control Hosp. Epidemiol. 2014, 35, 937-960. [CrossRef]

17. International Health Facility Guidelines-Part B, version 5, 2017-Hand Hygiene. Available online: http://www.healthfacilityguidelines.com/ViewPDF/ViewIndexPDF/iHFG_part_d_hand_hygiene (accessed on 2 March 2020).

18. Halabi, M.; Wiesholzer-Pittl, M.; Schöberl, J.; Mittermayer, H. Non-touch fittings in hospitals: A possible source of Pseudomonas aeruginosa and Legionella spp. J. Hosp. Infect. 2001, 49, 117-121. [CrossRef] [PubMed]

19. Merrer, J.; Girou, E.; Ducellier, D.; Clavreul, N.; Cizeau, F.; Legrand, P.; Leneveu, M. Should electronic faucets be used in intensive care and hematology units? Intensive Care Med. 2005, 31, 1715-1718. [CrossRef] [PubMed]

20. Decret 26.08.1993, n. 412. Regolamento Recante Norme per la Progettazione, L'installazione, L'esercizio e la Manutenzione Degli Impianti Termici Degli Edifici ai Fini del Contenimento dei Consumi di Energia, in Attuazione Dell'art. 4, Comma 4, Della Legge 09.01.1991, n. 10. G.U. Serie Generale n.242 14.10.1993-Suppl. Ordinario n. 96. Available online: https://www.bosettiegatti.eu/info/norme/statali/1993_0412.htm (accessed on 12 February 2020).

21. Vonberg, R.P.; Eckmanns, T.; Bruderek, J.; Rüden, H.; Gastmeier, P. Use of terminal tap water filter systems for prevention of nosocomial legionellosis. J. Hosp. Infect. 2005, 60, 159-162. [CrossRef] [PubMed]

22. Falkinham, J.O.; Pruden, A.; Edwards, M. Opportunistic Premise Plumbing Pathogens: Increasingly Important Pathogens in Drinking Water. Pathogens 2015, 4, 373-386. [CrossRef]

23. Liu, S.; Gunawan, C.; Barraud, N.; Rice, S.A.; Harry, E.J.; Amal, R. Understanding, Monitoring, and Controlling Biofilm Growth in Drinking Water Distribution Systems. Environ. Sci. Technol. 2016, 50, 8954-8976. [CrossRef]

24. Council Directive 98/83/EC of 3 November 1998 on the Quality of Water Intended for Human Consumption. Available online: http://data.europa.eu/eli/dir/1998/83/oj (accessed on 12 February 2020).

25. Commission directive (EU) 2015/1787 of 6 October 2015 Amending Annexes II and III to Council Directive 98/83/EC on the Quality of Water Intended for Human Consumption. Available online: http://data.europa. eu/eli/dir/2015/1787/oj (accessed on 12 February 2020).

26. D. Lgs. 02.02.2001, n.31. Directive 98/83/CE Relativa Alla Qualità Delle Acque Destinate al Consumo Umano. G.U. Della Repubblica Italiana n. 52, 03.03.2001. Available online: http://www.camera.it/parlam/leggi/ deleghe/01031dl.htm (accessed on 12 February 2020). 
27. DM 14.06.2017. Directive (UE) 2015/1787 che Modifica gli Allegati II e III Della Direttiva 98/83/CE Sulla Qualità Delle Acque Destinate al Consumo Umano. Modifica Degli Allegati II e III del Decreto Legislativo 2 Febbraio 2001, n. 31. G.U. Serie Generale n.192, 18.08.2017. Available online: http://www.si-t.eu/wordpress/ wp-content/uploads/2017/09/6.pdf (accessed on 12 February 2020).

28. World Health Organization. Guidelines for Drinking-Water Quality. 2011. Available online: http://apps.who. int/iris/bitstream/10665/44584/1/9789241548151_eng.pdf (accessed on 2 March 2020).

29. Exner, M.; Kramer, A.; Lajoie, L.; Gebel, J.; Engelhart, S.; Hartemann, P. Prevention and control of health care-associated waterborne infections in health care facilities. Am. J. Infect. Control 2005, 33, S26-S40. [CrossRef]

30. Falkinham, J.O.; Hilborn, E.D.; Arduino, M.J.; Pruden, A.; Edwards, M.A. Epidemiology and Ecology of Opportunistic Premise Plumbing Pathogens: Legionella pneumophila, Mycobacterium avium, and Pseudomonas aeruginosa. Environ. Health Perspect. 2015, 123, 749-758. [CrossRef]

31. Syndor, E.R.M.; Bova, G.; Gimburg, A.; Cosgrove, S.E.; Perl, T.M.; Maragakis, L.L. Electronic-Eye Faucets: Legionella Species Contamination in Healthcare Settings. Infect. Control Hosp. Epidemiol. 2012, 33, $235-239$. [CrossRef]

32. Charron, D.; Bédard, E.; Lalancette, C.; Laferrière, C.; Prévost, M. Impact of electronic faucets and water quality on the occurrence of Pseudomonas aeruginosa in water: A multi-hospital study. Infect. Control Hosp. Epidemiol. 2015, 36, 311-319. [CrossRef]

33. Rota, M.C.; Fontana, S.; Montaño-Remacha, C.; Scaturro, M.; Caporali, M.G.; Vullo, V.; Scorzolini, L.; Ercole, A.; Ricci, M.L. Legionnaires' disease pseudoepidemic due to falsely positive urine antigen test results. J. Clin. Microbiol. 2014, 52, 2279-2280. [CrossRef]

34. Svarrer, C.W.; Lück, C.; Elverdal, P.L.; Uldum, S.A. Immunochromatic kits Xpect Legionella and BinaxNOW Legionella for detection of Legionella pneumophila urinary antigen have low sensitivities for the diagnosis of Legionnaires' disease. J. Med. Microbiol. 2012, 61, 213-217. [CrossRef] [PubMed]

35. Girolamini, L.; Dormi, A.; Pellati, T.; Somaroli, P.; Montanari, D.; Costa, A.; Savelli, F.; Martelli, A.; Grottola, A.; Fregni Serpini, G.; et al. Advances in Legionella Control by a New Formulation of Hydrogen Peroxide and Silver Salts in a Hospital Hot Water Network. Pathogens 2019, 8, 209. [CrossRef] [PubMed]

36. Fliermans, C.B.; Cherry, W.B.; Orrison, L.H.; Smith, S.J.; Tison, D.L.; Pope, D.H. Ecological distribution of Legionella pneumophila. Appl. Environ. Microbiol. 1981, 41, 9-16. [CrossRef] [PubMed]

37. Berjeaud, J.M.; Chevalier, S.; Schlusselhuber, M.; Portier, E.; Loiseau, C.; Aucher, W.; Lesouhaitier, O.; Verdon, J. Legionella pneumophila: The Paradox of a Highly Sensitive Opportunistic Waterborne Pathogen Able to Persist in the Environment. Front. Microbiol. 2016, 7, 486. [CrossRef]

38. EN ISO 19458:2006-Water Quality-Sampling for Microbiological Analysis. Available online: https: //www.iso.org/standard/33845.html (accessed on 2 March 2020).

39. Liguori, G.; Cavallotti, I.; Arnese, A.; Amiranda, C.; Anastasi, D.; Angelillo, I.F. Microbiological quality of drinking water from dispensers in Italy. BMC Microbiol. 2010, 10, 19. [CrossRef]

40. ISO 11731:2017 Water quality-Enumeration of Legionella. International Organization for Standardization, Geneva, Switzerland. Available online: https://www.iso.org/standard/61782.html (accessed on 2 March 2020).

41. Ratcliff, R.M.; Lanser, J.A.; Manning, P.A.; Heuzenroeder, M.W. Sequence-based classification scheme for the genus Legionella targeting the mip gene. J. Clin. Microbiol. 1998, 36, 1560-1567. [CrossRef]

42. Mentasti, M.; Fry, N.K.; Afshar, B.; Palepou-Foxley, C.; Naik, F.C.; Harrison, T.G. Application of Legionella pneumophila specific quantitative real-time PCR combined with direct amplification and sequence-based typing in the diagnosis and epidemiological investigation of Legionnaires' disease. Eur. J. Clin. Microbiol. 2012, 8, 2017-2028. [CrossRef]

43. Fry, N.K.; Alexiou-Daniel, S.; Bangsborg, J.M.; Bernander, S.; Castellani Pastoris, M.; Etienne, J.; Forsblom, B.; Gaia, V.; Helbig, J.H.; Lindsay, D.; et al. A multi-center evaluation of genotypic methods for the epidemiological typing of Legionella pneumophila serogroup 1: Results of a pan-European study. Clin. Microbiol. Infec. 1999, 5, 462-477. [CrossRef]

44. Fry, N.K.; Afshar, B.; Bellamy, W.; Underwood, A.P.; Ratcliff, R.M.; Harrison, T.G. Identification of Legionella spp. by 19 European reference laboratories: results of the European Working Group for Legionella Infections External Quality Assessment Scheme using DNA sequencing of the macrophage infectivity potentiator gene and dedicated online tools. Clin. Microbiol. Infect. 2007, 13, 1119-1124. [CrossRef] 
45. Kimura, S.; Tateda, K.; Ishii, Y.; Horikawa, M.; Miyairi, S.; Gotoh, N. Pseudomonas aeruginosa Las quorum sensing autoinducer suppresses growth and biofilm production in Legionella species. Microbiology 2009, 155, 1934-1939. [CrossRef]

46. UNI EN ISO 16266:2008-Water Quality-Detection and Enumeration of Pseudomonas aeruginosa-Method by Membrane Filtration. International Organization for Standardization, Geneva, Switzerland. Available online: https://www.iso.org/standard/39272.html (accessed on 12 February 2020).

47. Wu, W.; Jin, Y.; Bai, F.; Jin, S. Chapter 41: Pseudomonas aeruginosa. Molecular Medical Microbiology (Second Edition), 2015, 2, 753-767. Available online: https://doi.org/10.1016/B978-0-12-397169-2.00041-X (accessed on 12 February 2020).

(C) 2020 by the authors. Licensee MDPI, Basel, Switzerland. This article is an open access article distributed under the terms and conditions of the Creative Commons Attribution (CC BY) license (http://creativecommons.org/licenses/by/4.0/). 